\title{
Defect structure and hardness in nanocrystalline CoCrFeMnNi High-Entropy Alloy processed by High-Pressure Torsion
}

\author{
Anita Heczel $^{1}$, Megumi Kawasaki ${ }^{2,3}$, János L. Lábár ${ }^{1,4}$, Jae-il Jang ${ }^{2}$, Terence G. Langdon ${ }^{3,5}$, \\ Jenő Gubicza ${ }^{1 *}$ \\ ${ }^{1}$ Department of Materials Physics, Eötvös Loránd University, Budapest, Hungary \\ ${ }^{2}$ Division of Materials Science and Engineering, Hanyang University, Seoul, Republic of \\ Korea \\ ${ }^{3}$ Departments of Aerospace \& Mechanical Engineering and Materials Science, \\ University of Southern California, Los Angeles, CA 90089-1453, U.S.A. \\ ${ }^{4}$ Institute for Technical Physics and Materials Science, Centre for Energy Research, \\ Hungarian Academy of Sciences, Budapest, Hungary \\ ${ }^{5}$ Materials Research Group, Faculty of Engineering and the Environment, University of \\ Southampton, Southampton SO17 1BJ, U.K. \\ *Corresponding author: Tel: + 36-1-372-2876, Fax: +36-1-372-2811, \\ e-mail: jeno.gubicza@ttk.elte.hu
}

\begin{abstract}
An equiatomic CoCrFeMnNi High-Entropy Alloy (HEA) produced by arc melting was processed by High-Pressure Torsion (HPT). The evolution of the microstructure during HPT was investigated after 1/4, 1/2, 1 and 2 turns using electron backscatter diffraction and transmission electron microscopy. The spatial distribution of constituents was studied by energy-dispersive X-ray spectroscopy. The dislocation density and the twin-fault probability in the HPT-processed samples were determined by X-ray line profiles analysis. It was found that the grain size was gradually refined from $\sim 60 \mu \mathrm{m}$ to $\sim 30 \mathrm{~nm}$ while the dislocation density and the twin-fault probability increased to very high values of about $194 \times 10^{14} \mathrm{~m}^{-2}$ and $2.7 \%$, respectively, at the periphery of the disk processed for 2 turns. The hardness evolution was measured as a function of the distance from the center of the HPT-processed disks. After 2 turns of HPT, the microhardness increased from $\sim 1440 \mathrm{MPa}$ to $\sim 5380 \mathrm{MPa}$ at the disk periphery where the highest straining is achieved. The yield strength was estimated as onethird of the hardness and correlated to the microstructure.
\end{abstract}

Keywords: High-Entropy Alloy, High-Pressure Torsion, X-ray Diffraction, Dislocations, Twin faults, Hardness 


\section{Introduction}

Conventional solid solutions are generally based on one principle element and other alloying atoms are added only in small concentrations for the improvement of properties. In the last decade, a new type of alloy concept, known as high entropy alloys (HEAs), was proposed [1,2]. HEAs are disordered solid solutions, containing five or more principal elements in equal or near-equal atomic ratios, in which all the atomic concentrations are between $5 \%$ and $35 \%$. The configurational entropy of a disordered solid solution is maximized by mixing a large number of alloying elements at near-equimolar concentrations and the high entropy of mixing stabilizes the disordered solid solution phases. These alloys are currently a focus of materials science due to their outstanding properties, such as high hardness and strength, good resistance to thermal softening, oxidation, wear and corrosion [1-6]. The high strength of HEA materials is caused by the strong resistance of the disordered crystal lattice to dislocation motion [7]. Therefore, a very high yield strength can be observed even for HEAs with large grain sizes [7]. It was shown that during plastic deformation (e.g., in uniaxial compression or impact loading) of HEAs at room-temperature, a large density of dislocations is formed which gives an additional contribution to hardening in agreement with the wellknown Taylor formula [7,8]. Therefore, plastic deformation at high strains may improve the strength of HEAs considerably.

Severe plastic deformation (SPD) is an effective tool for increasing the strength of materials $[9,10]$. During SPD processing both grain refinement and an increase in dislocation density may contribute to hardening. High-pressure torsion (HPT) is one of the most effective SPD techniques for achieving high strength in structural materials [11]. HPT processing is expected to yield an additional improvement in hardness of HEAs. Indeed, HPT-straining for a face-centered cubic (fcc) CoCrFeNiMn HEA resulted in an improvement in hardness due to the reduction of grain size into the nanocrystalline regime [12]. In an $\mathrm{Al}_{0.3} \mathrm{Cu}_{0.5} \mathrm{CoCrFeNi}$ HEA, HPT processing led to both significant grain refinement to about $50 \mathrm{~nm}$ and homogenization of the elemental distribution [13]. It should be noted that annealing at appropriate temperatures after HPT may yield additional hardening due to the formation of secondary phase particles, as with an ordered body-centered cubic phase in fcc $\mathrm{Al}_{0.3} \mathrm{CoCrFeNi}$ HEA [14].

One of the most frequently studied HEAs has the composition of CoCrFeNiMn. The crystal structure and the mechanical properties of this alloy have been studied intensively [1519]. However, the evolution of the lattice defects, such as dislocations or twin-faults, during HPT and their influence on the mechanical behaviour have not been investigated. In the 
present work, the effect of HPT processing on the microstructure and the hardness of an equimolar CoCrFeMnNi HEA material was investigated. The evolution of the grain size, the dislocation density and the twin-fault probability was determined at the center and the periphery of the disks processed by HPT up to 2 turns. The detailed characterization of the lattice defect structure was carried out with a combination of X-ray line profile analysis (XLPA), electron backscatter diffraction (EBSD) and transmission electron microscopy (TEM). The hardness was determined as a function of both distance from the center of the HPT disk and numbers of turns. The relationship between the hardness and the microstructure for the HPT-processed equimolar CoCrFeMnNi HEA is discussed in detail.

\section{Material and experimental procedures}

\subsection{Sample processing}

A HEA material with the composition of $\mathrm{Co}_{20} \mathrm{Cr}_{20} \mathrm{Fe}_{20} \mathrm{Mn}_{20} \mathrm{Ni}_{20}$ (in at.\%) was prepared by arc-melting of a mixture of pure metals (purity > 99 wt.\%) in a Ti-gettered high-purity Ar atmosphere. The ingots were remelted at least four times to promote chemical homogeneity. The melted alloys were then drop-cast into a mold with dimensions of $10 \mathrm{~mm} \times 10 \mathrm{~mm} \times 60$ $\mathrm{mm}$. The as-cast samples (disks having a diameter of $\sim 10 \mathrm{~mm}$ and a thickness of $\sim 0.8 \mathrm{~mm}$ ) were subjected to HPT at room temperature (RT) under quasi-constrained conditions [20] using a rate of $1 \mathrm{rpm}$ under a pressure of $3.0 \mathrm{GPa}$. The applied numbers of turns were 1/4, 1/2, 1 and 2.

\subsection{Electron microscopy}

The microstructure was studied in the initial as-cast sample as well as at the center and the periphery of the HPT processed disks where the imposed strain values were the lowest and the highest, respectively, for any given turn. The evolution of the microstructure was investigated by electron backscatter diffraction (EBSD) using an FEI Quanta 3D scanning electron microscope (SEM). The step size varied between 25 and $250 \mathrm{~nm}$ depending on the dimensions of the images. Before the EBSD investigation the surface was mechanically polished with 1200, 2500 and 4000 grit SiC abrasive papers and then the polishing was continued with a colloidal silica suspension (OP-S) with a particle size of $40 \mathrm{~nm}$. Finally, the surface was electropolished at $25 \mathrm{~V}$ and $1 \mathrm{~A}$ using an electrolyte with a composition of $70 \%$ ethanol, $20 \%$ glycerine and $10 \%$ perchloric acid (in vol.\%). At the periphery of the disks processed for $1 / 2$, 1 and 2 turns, EBSD was not capable of evaluating the strongly refined and distorted microstructure. Therefore, transmission electron microscopy (TEM) investigations were 
applied for the determination of the grain size at the disk peripheries for $1 / 2,1$ and 2 revolutions. The TEM foils were thinned first by mechanical grinding to a thickness of $50 \mu \mathrm{m}$ and then they were ion milled using an Ar ion beam at an inclination angle of $5^{\circ}$ until perforation. The ion milling was conducted at $7 \mathrm{keV}$ and $2 \mathrm{~mA}$ with continuous cooling of the sample by liquid nitrogen. The TEM images were taken using a Philips CM-20 transmission electron microscope operating at $200 \mathrm{kV}$. The twin faults inside the nanocrystals formed due to HPT were studied with a higher magnification using a JEOL-3010 transmission electron microscope operating at $300 \mathrm{kV}$. The TEM pictures were detected by a GATAN Orius CCD camera using Digital Micrograph software. The spatial distribution of the chemical elements was measured by energy-dispersive X-ray spectroscopy (EDS) in SEM.

\subsection{X-ray diffraction}

The average lattice parameter for the HEA samples was investigated by X-ray diffraction (XRD) using a Philips Xpert $\Theta-2 \Theta$ powder diffractometer operating at $40 \mathrm{kV}$ and $30 \mathrm{~mA}$ with $\mathrm{CuK} \alpha$ radiation (wavelength: $\lambda=0.15418 \mathrm{~nm}$ ). The measured XRD patterns indicate that all the studied samples have face-centered cubic (fcc) structure. The average lattice parameter was determined from the diffraction peak positions using the Nelson-Riley method [21].

The lattice defect structure in the center and the peripheral parts of the HPT-processed disks was studied by X-ray line profile analysis (XLPA). The X-ray line profiles were measured using a high-resolution diffractometer with $\mathrm{CoK} \alpha 1$ radiation (wavelength: $\lambda=$ $0.1789 \mathrm{~nm}$ ). Two-dimensional imaging plates detected the Debye-Scherrer diffraction rings. The diffraction profiles were evaluated by the Convolutional Multiple Whole Profile (CMWP) method [22]. In this method, the diffraction pattern is fitted by the sum of a background spline and the convolution of the instrumental pattern and the theoretical line profiles. The details of the measurement of the instrumental pattern and its significance in the XLPA evaluation are discussed in section 3.3. The CMWP method gives the diffraction domain size, the dislocation density and the twin fault probability with good statistics, where the twin fault probability in fcc materials is defined as the relative fraction of twin boundaries among the $\{111\}$ lattice planes. The area-weighted mean diffraction domain size $\left(\langle x\rangle_{\text {area }}\right)$, the dislocation density $(\rho)$ and the twin fault probability $(\beta)$ were obtained from the fitting. The $\langle x\rangle_{\text {area }}$ was calculated from the median $(m)$ and the log-normal variance $\left(\sigma^{2}\right)$ of the diffraction domain size distribution as: $\langle x\rangle_{\text {area }}=m \exp \left(2.5 \sigma^{2}\right)$. It is noted that the size of the $\mathrm{X}$-ray beam spot on the sample surface was about $1 \times 0.3 \mathrm{~mm}^{2}$, as shown in Fig. 1 . Therefore, the results obtained in the disk center should be considered as an average for distances from 
the center between -0.5 and $0.5 \mathrm{~mm}$. At the periphery, the XLPA measurement was carried out at $1 \mathrm{~mm}$ from the edge and therefore at a distance of $4 \mathrm{~mm}$ from the disk center.

\subsection{Hardness testing}

The microhardness along the radius of the HPT disks was measured using a Zwick Roell $\mathrm{ZH} \mu$ Vickers indenter with an applied load of $500 \mathrm{~g}$ and a dwell time of $10 \mathrm{~s}$. The spacing between the neighbouring indents was $0.5 \mathrm{~mm}$.

\section{Results}

\subsection{Microstructure and elemental distribution in the as-cast material}

The measured X-ray diffractograms indicated that the initial material is a single phase facecentered cubic (fcc) structure with a lattice parameter of $a=0.3599 \pm 0.0001 \mathrm{~nm}$. Neither the structure nor the lattice parameter changed during HPT. Figs. 2a and b show EBSD and backscattered electron (BSE) SEM images for the as-cast microstructure, respectively. In the EBSD image, a preferred crystallographic orientation of the grains is not observed (see Fig. 2a). The grains were considered as the regions in the EBSD images bounded by high-angle grain boundaries (HAGBs) with misorientations larger than $15^{\circ}$. In the initial sample, the grain size values have a broad distribution between 10-250 $\mu \mathrm{m}$ with a number-weighted average value of $\sim 60 \mu \mathrm{m}$. The EDS analysis performed at different areas revealed that the elemental fractions deviate slightly from the nominal equimolar chemical composition. Namely, the atomic concentrations for $\mathrm{Co}, \mathrm{Cr}, \mathrm{Fe}, \mathrm{Mn}$ and $\mathrm{Ni}$ are $20.1 \pm 1.3,20.9 \pm 3.7,20.4$ $\pm 3.0,19.4 \pm 4.5$ and $19.3 \pm 3.3$ at.\%, respectively, as measured on twenty five randomly selected areas in the initial sample. The uncertainties of the values were calculated from the differences in the concentrations obtained on the various areas. The BSE images in Figs. $2 b$ and $\mathrm{c}$ reveal a dendritic-like microstructure in the initial sample. The fractions of the five constituents in the as-cast $\mathrm{CoCrFeMnNi}$ were determined along the white dotted line (perpendicular to the dendritic arms) in Fig. 2c by EDS and the results are shown in Fig. 2d. An inhomogeneous spatial distribution of the five chemical elements with a periodicity of $\sim 8$ $\mu \mathrm{m}$ is revealed. The atomic concentrations of $\mathrm{Co}, \mathrm{Cr}$ and Fe vary in a complementary manner with the $\mathrm{Ni}$ and $\mathrm{Mn}$ contents. Thus, where the $\mathrm{Co}, \mathrm{Cr}$ and $\mathrm{Fe}$ concentrations increase to 22-23 at. $\%$, the $\mathrm{Ni}$ and $\mathrm{Mn}$ fractions decrease to 16-18 at.\%. The largest concentration fluctuations were observed for $\mathrm{Fe}$ and $\mathrm{Mn}$. This result is in accordance with former studies (e.g., [23]) which showed that the dendritic areas in an as-cast $\mathrm{CoCrFeMnNi} \mathrm{HEA}$ are enriched in $\mathrm{Co}, \mathrm{Cr}$ and $\mathrm{Fe}$ and depleted of $\mathrm{Ni}$ and $\mathrm{Mn}$. 


\subsection{Evolution of the microstructure and the elemental distribution during $H P T$}

Figs. $3 \mathrm{a}, \mathrm{b}$ and $\mathrm{c}$ show the microstructures at the center, half radius and periphery of the HPT disk processed for 1/4 revolution. The number-weighted average grain size was measured as $\sim 33 \mu \mathrm{m}$ in the center of the disk which is smaller by a factor of two than in the as-cast specimen (see Fig. 3a). The microstructure at the half-radius was studied only for this sample as previous investigations on $\mathrm{CoCrFeMnNi} \mathrm{HEA} \mathrm{suggested} \mathrm{that} \mathrm{significant} \mathrm{twinning} \mathrm{occurs}$ in this material even at small shear strains (above the shear strain of 0.5 [15]). Indeed, Fig. 3b reveals considerable twinning at the half-radius of the sample processed for $1 / 4$ turn. The twins are indicated by white arrows in the figure. The average twin boundary spacing is about $1 \mu \mathrm{m}$. It is noted that the shear strain for the location shown in Fig. $3 \mathrm{~b}$ is about 5.6 which is much higher than the above mentioned critical shear strain for twinning in $\mathrm{CoCrFeMnNi}$ HEA. Fig. 3c shows that the number-weighted average grain size was reduced to $\sim 233 \mathrm{~nm}$ at the periphery of the disk. The two orders of magnitude smaller grain size at the periphery compared to the center in the disk processed by $1 / 4$ turn indicates a very rapid grain refinement in this HEA with increasing shear strain during HPT processing. The grain size values obtained by microscopic methods are listed in Table 1.

Figs. 4a-c show EBSD images taken at the centers of the disks processed by HPT for 1/2, 1 and 2 turns, respectively. Table 1 reveals that between 1/4 and 1/2 turns the numberweighted average grain size in the disk center decreased to about $19 \mu \mathrm{m}$. Between $1 / 2$ and 1 turn, the grain size was refined from $\sim 19$ to $\sim 4.8 \mu \mathrm{m}$ in the center of the HPT-processed disks. After 2 turns, the number-weighted average grain size decreased to $\sim 3.7 \mu \mathrm{m}$ in the disk center. In addition to the grain refinement, twins were also formed inside the grains as illustrated for 1 turn in Fig. 4d which was obtained by magnifying a part of Fig. 4b. The $\Sigma 3$ boundaries in Fig. 4d are represented by thick black lines and some twinned regions are indicated by white arrows. The mean spacing between the twin boundaries is $\sim 3 \mu \mathrm{m}$, as estimated from the EBSD images.

As already mentioned, due to the heavily distorted microstructure at the disk peripheries for 1/2, 1 and 2 turns, the microstructures at these locations were investigated by TEM. Figs. 5a, b and c show representative dark-field (DF) TEM images for the samples processed by 1/2, 1 and 2 turns. The average grain sizes determined from the TEM images 
were $\sim 37, \sim 34$ and $\sim 27 \mathrm{~nm}$ for 1/2, 1 and 2 turns, respectively. About one hundred and fifty grains were evaluated for the calculation of the average grain size.

The bright-field TEM images in Fig. 6 illustrate that twin faults with a high frequency were formed inside the nanograins at the periphery of the disk processed by 1 turn of HPT. Some nanotwinned lamellae are indicated by black arrows. The twin fault spacing varies between 1 and $10 \mathrm{~nm}$ in the nanocrystals shown in Fig. 6. By comparison, in the center of the same disk the twin boundary spacing was about $\sim 3 \mu \mathrm{m}$ as shown in Fig. 4 d. This observation suggests that, in addition to the decrease in grain size, the twin fault frequency was enhanced significantly with increasing imposed strain in HPT processing.

The elemental distributions were also investigated in the center and the periphery of the disks processed by the lowest (1/4) and the highest (2) numbers of HPT turns. The EDS results are shown in Fig. 7. The inhomogeneous chemical element distribution in the initial material was inherited in the HPT-processed samples (see Fig. 3). Due to HPT processing, although the frequency of concentration oscillations decreased, the concentration differences did not change considerably (compare Figs. $2 \mathrm{~d}$ and $7 \mathrm{~d}$ ). Similar to the initial state, the atomic concentrations of $\mathrm{Co}, \mathrm{Cr}$ and $\mathrm{Fe}$ vary in a complementary way with the $\mathrm{Ni}$ and $\mathrm{Mn}$ contents and the largest concentration fluctuations were observed for Fe and Mn.

\subsection{Microstructure of the HPT-processed HEA samples from XLPA}

The initial as-cast CoCrFeMnNi HEA exhibited broader X-ray diffraction peaks than the profiles measured on a standard $\mathrm{LaB}_{6}$ standard material. Most probably, this broadening is caused by the chemical inhomogeneities in the present as-cast HEA sample (see Fig. 2d). The heterogeneous chemical composition yields a variation in the lattice spacings which leads to an X-ray diffraction profile broadening even in the as-cast HEA sample before HPT. As shown by the EDS analysis, the magnitude of the concentration fluctuations do not decrease during HPT, therefore the chemical inhomogeneities alone would have caused similar diffraction peak broadening for the HPT-processed samples as in the initial state. However, in addition to this effect the peaks measured on the HPT disks broadened also due to the increase of the lattice defect (e.g., dislocations and twin faults) density and the reduction of the diffraction domain size. The diffraction peak caused by these effects can be referred to as the microstructural profile. Since only moderate chemical heterogeneities were observed in the present HEA samples, therefore it was assumed that the microstructure is not influenced by the slightly different chemical compositions in the various volumes of the material. With this condition, the microstructural X-ray diffraction profile components scattered from the 
different regions with various concentrations have the same profile shape except that their positions and intensities are different due to the various lattice spacings and volumes.

Fig. 8 shows schematically how these profile components build up the measured diffraction peak. Accordingly, the total intensity profile $(I(\kappa))$ can be expressed as:

$$
I(\kappa)=\int f(g) I^{m s}(\kappa-g) d g,
$$

where $\kappa$ and $g$ are the modulus of the scattering and diffraction vectors, respectively $(\kappa=$ $2 \sin \theta / \lambda$ while $g=2 \sin \theta_{B} / \lambda$ where $\theta$ and $\theta_{B}$ are the scattering and Bragg angles, respectively). $I^{m s}(\kappa-g)$ are the subprofiles caused by the microstructure and normalized to a unit peak intensity. $f(g)$ is the density distribution function of the diffraction vector caused by the chemical heterogeneities which reflects the distribution of the lattice spacings $(d)$ since $g=1 / d$. According to eq. (1), the total intensity can be given as:

$$
I(\kappa)=f(\kappa) * I^{m s}(\kappa),
$$

where $*$ represents convolution. If the instrumental effect is also taken into account, the diffraction peak profile can be obtained as:

$$
I(\kappa)=I^{i}(\kappa) * f(\kappa) * I^{m s}(\kappa),
$$

where $I^{i}(\kappa)$ is the instrumental profile. As the lattice defect density in the coarse-grained initial as-cast material is negligible compared to the HPT-processed samples, the profiles measured for the initial specimen $\left(I^{\text {init }}(\kappa)\right)$ gives $I^{i}(\kappa) * f(\kappa)$. Therefore, the total intensity is expressed as:

$$
I(\kappa)=I^{i n i t}(\kappa) * I^{m s}(\kappa)=I^{i n i t}(\kappa) * I^{s}(\kappa) * I^{d}(\kappa) * I^{t f}(\kappa),
$$

where $I^{s}(\kappa), I^{d}(\kappa)$ and $I^{t f}(\kappa)$ are the intensity profiles for diffraction domain size, dislocations and twin faults, respectively. In the XLPA evaluation of the HPT-processed samples, the diffraction peaks were fitted by the convolution if the intensity profile measured on the initial sample and the peak functions calculated theoretically for the effects of the diffraction domain size, dislocations and twin faults. In this evaluation, it is assumed that HPT processing does not produce a considerable reduction in the concentration fluctuations, in accordance with the EDS measurements, so that the profile measured on the initial specimen is also a good approximation for $I^{i}(\kappa) * f(\kappa)$ in the HPT-processed samples.

Fig. 9a shows reflection 200 for the initial material and the two HPT-processed states for the lowest (in the center of the disk processed for 1/4 turn) and the highest (at the periphery of the disk processed for 2 turns) imposed strains. The peak broadening of the initial sample is caused by the instrumental broadening and the chemical heterogeneities, as discussed above. The latter effect yielded a slightly asymmetric peak shape, as revealed in 
Fig. 9a. HPT processing led to a significant increase in the profile breadth even in the center of the disk processed for 1/4 turn. The peak broadening further increased for the periphery after 2 turns due to the much larger deformation. The dependence of the peak breadths on the diffraction order (on the indices $h k l$ ) can be visualized by plotting the integral breadth of the profiles (the total area under the peak divided by the peak height) as a function of the modulus of the diffraction vector, $g$ (Williamson-Hall plot) [24,25]. Fig. 9b shows Williamson-Hall plots for the initial material, the center of the disk processed for $1 / 4$ turn and the periphery of the disk processed for 2 turns. The significantly non-monotonous variation of the integral breadth as a function of $g$ for the HPT-processed samples is caused by the lattice defects such as dislocations and twin-faults. For dislocations with mixed edge/screw character, the breadths of 200, 220 and 222 reflections are close to each other, while the width of 311 reflection is much larger [25]. This can be observed for the measurement obtained at the center of the disk processed for 1/4 turn. At the same time, the relatively large peak breadth of reflection 200 for the periphery of the disk processed for 2 turns suggests considerable twinfault probability. For dislocations, the dependence of peak broadening on the reflection indices $h k l$ can be taken into account by the average contrast factors. The average contrast factors for reflection $h k l, \bar{C}_{h k l}$, can be calculated numerically from the anisotropic elastic constants of the crystal [25]. The values of the elastic constants $c_{11}, c_{12}$ and $c_{44}$ are 172, 108 and $92 \mathrm{GPa}$, respectively, for the present HEA composition [26].

The average contrast factor can be expressed as:

$$
\bar{C}_{h k l}=\bar{C}_{h 00}\left(1-q \frac{h^{2} k^{2}+k^{2} l^{2}+h^{2} l^{2}}{\left(h^{2}+k^{2}+l^{2}\right)^{2}}\right),
$$

where $\bar{C}_{h 00}$ is the contrast factor for reflection $h 00$ and $q$ depends on the edge/screw character of dislocations. The values of $\bar{C}_{h 00}$ for edge and screw dislocations were calculated as 0.278 and 0.283, respectively, using program ANIZC [27]. The values of $q$ for edge and screw dislocations were obtained as 1.5 and 2.3 , respectively. Using the average contrast factors, the diffraction domain size, the dislocation density and the twin fault probability can be determined by fitting the calculated theoretical patterns to the experimental diffractograms using the CMWP procedure [22,28]. Fig. 9c shows a CMWP fitting for the center of the disk processed by $1 / 4$ turn.

The average diffraction domain size, dislocation density and twin fault probability determined for the center and the periphery of the disks processed by 1/4, 1/2, 1 and 2 turns of HPT are listed in Table 1. It can be seen that the dislocation density is very large $\left(\sim 43 \times 10^{14}\right.$ 
$\mathrm{m}^{-2}$ ) in the center of the disk processed by $1 / 4$ turn, while the grain structure was only slightly refined (the grain size decreased from $\sim 60 \mu \mathrm{m}$ to $\sim 33 \mu \mathrm{m}$ as shown by the EBSD study in section 3.2). The dislocation density increased with increasing numbers of HPT turns up to 1 revolution in both the center and the periphery of the disks. Between 1 and 2 turns only a slight difference between the dislocation density values was observed. The maximum dislocation densities with the values of $\sim 126 \times 10^{14} \mathrm{~m}^{-2}$ and $\sim 194 \times 10^{14} \mathrm{~m}^{-2}$ were measured in the center and the periphery of the disk processed for 2 turns, respectively. It can be seen from Table 1 that the difference between the dislocation densities in the center and the periphery remained significant even after 2 turns of HPT, and this is similar to the hardness values presented in the next section.

For the center parts of all disks and also in the peripheries after $1 / 4$ and 1/2 turns, the twin fault probability remained under the detection limit of XLPA (about 0.1\% which corresponds to a twin fault spacing of $\sim 200 \mathrm{~nm}$ ). This observation is not in contradiction with the detection of twin faults in the EBSD images taken in the centers of the disks processed by 1 and 2 turns (for 1 turn see Fig. 4d) since the twin fault spacing is $\sim 3 \mu \mathrm{m}$ which is much larger than the upper limit of detection in XLPA. However, considerable twin fault probability values $(\beta)$ of $\sim 2.2 \%$ and $\sim 2.7 \%$ were observed in the peripheral parts of the disks processed by 1 and 2 turns, respectively. These values correspond to a mean twin fault spacing of about 8-10 $\mathrm{nm}$ which is in accordance with the twin fault spacing observed by TEM (see section 3.2). The twin fault spacing can be calculated from $\beta$ as $100 \cdot d_{111} / \beta$ where $d_{111}$ is the lattice spacing for planes $\{111\}$. The deviation of the twin fault spacing determined by TEM from the value obtained by XLPA can be attributed to the much larger volume studied by the latter method. The high twin fault probability at the periphery of the disk processed by 2 turns is in accordance with the relatively large breadth of reflection 200 in the Williamson-Hall plot (see Fig. 9b) as discussed above.

The diffraction domain size is very small $(\sim 51 \mathrm{~nm})$ in the center of the disk processed by $1 / 4$ turn. This value is about three orders of magnitude smaller than the grain size measured by EBSD. The difference between the diffraction domain size obtained by XLPA and the grain size determined by microscopic methods in SPD-processed materials is a well known phenomenon. The diffraction domains are equivalent to the volumes scattering $\mathrm{X}$-rays coherently. Dislocation patterns inside the grains may break the coherency of X-rays. Lowangle grain boundaries and dipolar dislocation walls are typical examples which fragment grains into small diffraction domains. The high dislocation density yielded a small diffraction domain size in the center of the HEA sample processed by $1 / 4$ turn. With increasing distance 
from the center and the numbers of turns, the grain size was strongly reduced while only a small decrease in the diffraction domain size was detected. Therefore, the difference between the grain and diffraction domain sizes decreased with increasing strain during HPT. For the peripheries of the disks processed by 1/2, 1 and 2 turns, the grain and diffraction domain sizes agree within the experimental error. The smallest grain and diffraction domain sizes were 20$30 \mathrm{~nm}$ which were achieved after 1/2 turn at the periphery of the HPT disk.

The grain size determined by EBSD or TEM, the diffraction domain size and the dislocation density obtained by XLPA were plotted in Figs. 10a, b and c, respectively, as a function of shear strain given as $\gamma=2 \pi r N / h$, where $r, h$ and $N$ are the distance from the center, the thickness of the HPT processed disk and the number of turns, respectively. It should be noted that, due to the $1 \mathrm{~mm}$ height of the X-ray spot on the illuminated surface, for the diffraction domain sizes and the dislocation densities determined in the center of the disks the shear strain was obtained by averaging the strain values obtained for distances from the disk center between -0.5 and $0.5 \mathrm{~mm}$. For the dislocation densities and diffraction domain sizes measured near the periphery, the shear strain was determined at $4 \mathrm{~mm}$ from the disk center (see Fig. 1). Fig. 10 shows that the grain and the diffraction domain sizes saturated even at the shear strain of $\sim 10$ while the dislocation density reached its maximum value only at the shear strain of $\sim 40$. It is noted that, although the nominal value of the shear strain is zero in the center of the disks, the grain size decreased considerably with increasing numbers of turns (see Table 1). This discrepancy can be explained by the spread of plastic deformation into the center from the neighboring regions due to the stress field of dislocations developed out of the disk center. This induced plasticity causes grain refinement even in the disk center.

\subsection{Hardness evolution during HPT}

Fig. 11a shows the hardness evolution along the disk diameter as a function of the number of rotations. The undeformed specimen has a hardness of about $1440 \mathrm{MPa}$. After 1/4 turn of HPT there is a large gradient in the hardness along the disk radius. In the center and the periphery, the hardness values are $\sim 2400$ and $\sim 4860 \mathrm{MPa}$, respectively. Further straining up to $1 / 2$ turn yielded a slight hardening in both the center and the periphery. In addition, the hard regions at the periphery expanded towards the disk center as shown in Fig. 11a. Between 1/2 and 1 turn of HPT, the hardness increased from $\sim 2520 \mathrm{MPa}$ to $\sim 3180 \mathrm{MPa}$ in the center of the disks. At the periphery, the hardness was enhanced to $\sim 5220 \mathrm{MPa}$. Moreover, the hard regions expanded further towards the disk center. Between 1 and 2 turns of HPT, only a slight increase of the hardness was detected. The maximum value of the hardness was measured at 
the periphery of the disk processed by 2 turns $(\sim 5380 \mathrm{MPa})$. However, even after 2 turns of HPT a relatively low hardness remained in the disk center. It is probable that higher numbers of turns may yield a complete saturation of hardness with a large value along the disk radius.

Fig. $11 \mathrm{~b}$ shows that the hardness values measured at different distances from the disk centers for various numbers of turns follow a unified trend if they are plotted as a function of the shear strain. Specifically, this trend shows the general hardness evolution associated with strain hardening observed in many commercial purity metals and simple alloys after HPT processing. A recent report summarizes the different models of hardness evolution in various metallic materials processed by HPT [29]. It should be noted that the hardness increased in the disk center with increasing number of turns although the nominal shear strain there is zero. This can be explained by the spread of plasticity from the neighboring regions into the disk center (see section 3.3).

\section{Discussion}

\subsection{Evolution of lattice defect structure in CoCrFeMnNi HEA during HPT}

The defect structure in the CoCrFeMnNi HEA was mainly studied by XLPA. For conventional metals and alloys, the diffraction peak profiles are broadened primarily due to the instrumental effect, the finite diffraction domain size, dislocations and planar faults. At the same time, in HEAs the chemical heterogeneities may yield spatial variations of the lattice constant which give an additional contribution to X-ray line broadening. Without the knowledge of this broadening effect, the real values of the dislocation density and the twin fault probability cannot be determined by XLPA. In section 3.3, a simple solution was proposed for taking into account the broadening effect of moderate chemical heterogeneities in the evaluation of diffraction peak profiles of severely deformed HEAs. In this method, the pattern measured on the initial coarse-grained HEA was used as an instrumental diffractogram instead of the pattern measured on the line profile standard material (and thus on $\mathrm{LaB}_{6}$ ). For the present CoCrFeMnNi HEA, the peak breadths of the initial HEA sample were three times larger than the line widths for the $\mathrm{LaB}_{6}$ standard. In this modified analysis, it was assumed that the lattice defect structure does not depend strongly on the chemical composition in the material, which is certainly valid only for slight concentration fluctuations as in the present case. This method can be used for any plastically deformed HEA. It should be noted, however, that there may be HEA samples for which the chemical heterogeneities are very low, therefore the diffractogram measured on $\mathrm{LaB}_{6}$ can be used as an instrumental pattern in the line profile analysis. For instance, our recent study on a $\mathrm{Ti}_{20} \mathrm{Zr}_{20} \mathrm{Hf}_{20} \mathrm{Nb}_{20} \mathrm{Ta}_{20} \mathrm{HEA}$ 
revealed no significant difference between the peak breadths measured on the initial coarsegrained sample and the $\mathrm{LaB}_{6}$ standard material due to the negligible concentration fluctuations in the HEA specimen.

It was found for the present CoCrFeMnNi HEA that for low shear strains of HPT (in the center part of the disk processed by $1 / 4$ turn) the dislocation density increased to very high values $\left(10^{15}-10^{16} \mathrm{~m}^{-2}\right)$ while the grain size was only slightly refined. This observation suggests that the rate of increase of the dislocation density is higher than for the grain refinement. A fast increase in the dislocation density without considerable grain refinement was also observed during compression of another HEA with the equimolar composition of TiZrHfNbTa in earlier work [7]. The high dislocation densities in plastically deformed HEAs, even at low strains, can be explained by a reduced annihilation rate of dislocations during plastic deformation which may be caused by the high stress required for dislocation motion in highly-alloyed HEA materials. In addition, for the present CoCrFeMnNi HEA the low stacking fault energy (SFE, $19 \mathrm{~mJ} / \mathrm{m}^{2}$ [30]) also contributed to the very high dislocation density. The low SFE results in a dissociation of dislocations into partials which obstructs the annihilation mechanisms of dislocations as in cross slip and climb [31]. Therefore, both the high concentrations of the different alloying elements and the low SFE are the reasons for the very high dislocation density $\left(\sim 194 \times 10^{14} \mathrm{~m}^{-2}\right)$ after 2 turns of HPT. In addition, the high twin fault probability inside the nanograins after 1-2 turns (2.2-2.7\%) was also caused mainly by the low SFE of this HEA. A similar twin fault probability (about 2\%) was also obtained for a HPT processed $4 \mathrm{~N}$ purity Ag with a similar SFE $\left(\sim 16 \mathrm{~mJ} / \mathrm{m}^{2}\right)$ [32]. The saturation dislocation density achieved in the Ag sample $\left(\sim 154 \times 10^{14} \mathrm{~m}^{-2}\right)$ was also close to the value measured for the present HEA material $\left(\sim 194 \times 10^{14} \mathrm{~m}^{-2}\right)$. Therefore, it seems that the low SFE of $\mathrm{CoCrFeMnNi} \mathrm{HEA}$ is a deterministic factor in the evolution of the defect structure during HPT. It is noted that a recently published study [33] showed that in a CoCrFeMnNi HEA the value of SFE may have a spatial dependence due to the variation of local chemical composition. This effect yields a different degree of dislocation dissociation into partials. It was revealed that in the CoCrFeMnNi HEA deformed to a plastic strain of 5\% the splitting distance between the partials in dissociated dislocations varies between 1 and $9 \mathrm{~nm}$. The mean and the standard deviation of the splitting distance were 5 and $2 \mathrm{~nm}$, respectively. These values are in reasonable agreement with the splitting distances in Ag ( 2.5 and $\sim 6.3 \mathrm{~nm}$ for screw and edge dislocations, respectively [34]) with similar SFE.

It should be noted that the present results are in accordance with former studies on HPT-processed CoCrFeMnNi HEA. In the investigation performed by Schuh et al. [15] the 
applied HPT pressure was higher $(7.8 \mathrm{GPa})$ while the rate of deformation was lower $(0.2 \mathrm{rpm})$ than in these experiments (3.0 GPa and $1 \mathrm{rpm}$ ). Despite the different HPT conditions, the saturation grain size $(\sim 50 \mathrm{~nm})$ and hardness $(\sim 5100 \mathrm{MPa})$ were very close to the values obtained in this study ( $\sim 30 \mathrm{~nm}$ and $\sim 5380 \mathrm{MPa})$. In addition, the threshold shear strain for hardness saturation was observed as $~ 50$ in earlier work. [15] which is very close to the value determined in this study ( 45, see Fig. 11b). Concerning lattice defects formed during HPT, both the former and the present studies revealed the significance of twinning in plastic deformation of $\mathrm{CoCrFeMnNi} \mathrm{HEA} \mathrm{even} \mathrm{for} \mathrm{low} \mathrm{numbers} \mathrm{of} \mathrm{turns} \mathrm{(see} \mathrm{Fig.} \mathrm{3b).} \mathrm{Considerable}$ twin formation was also observed in cold rolled and tensile tested CoCrFeMnNi HEA [35,36]. The critical shear strain for twinning was determined as $\sim 0.5[15,36]$, therefore the observation of significant twinning even at the half-radius of the disk processed for 1/4 turn (where the shear strain is $~ 5.6$ ) is in accordance with the results presented in the literature. XLPA is unable to observe twin faults for low numbers of HPT turns since this method can detect twin boundaries only if their average spacing is lower than $200 \mathrm{~nm}$. Therefore, XLPA gives considerable twin fault probability only for the periphery of the disks processed by 1 and 2 turns, despite the significant twinning for lower numbers of turns. It should also be noted that the lower twin fault probability for small numbers of HPT turns does not represent necessarily a lower contribution of twinning to plasticity as the shear strain caused by twinning is determined by the volume of the twinned regions and not by the amount of twin boundaries.

Our study also revealed a very high twin fault probability at the peripheries of the disks processed by 1 and 2 turns where the shear strain reached the values of $\sim 36$ and $\sim 74$, respectively. This observation differs from the results of Schuh et al. [15] who only scarcely detected twins inside the nanograins in $\mathrm{CoCrFeMnNi} \mathrm{HEA} \mathrm{deformed} \mathrm{by} \mathrm{HPT} \mathrm{up} \mathrm{to} \mathrm{the} \mathrm{shear}$ strain of $\sim 50$. This apparent contradiction can be attributed to the blurry scanning TEM (STEM) image used for the study of twinning in the former work (see Fig. 3a in Ref. [15]). In the present study, the method of XLPA was used for the determination of twin fault probability which has a much better statistics than STEM. The volume studied by XLPA is at least six orders of magnitude larger than that investigated by STEM in [15]. Moreover, the good quality TEM images in Fig. 6 visualized the existence of twin faults with high density in the CoCrFeMnNi HEA processed by HPT up to high strain values. It should be emphasized again that XLPA works well only above a certain limit of twin fault probability $(\sim 0.1 \%$ which corresponds to an average twin spacing of $\sim 200 \mathrm{~nm}$ ). 


\subsection{Strengthening mechanisms in the HPT-processed CoCrFeMnNi HEA}

In order to reveal the underlying strengthening mechanisms in the present HEA processed by HPT, the yield strength was estimated as one-third of the hardness in the center and the periphery and then compared with the values calculated as the sum of the dislocation and grain size hardening contributions. It is noted that the ratio of the hardness and the yield strength depends on the work hardening behavior of the material as the hardness measurement itself causes a plastic strain of $8 \%$ in the sample. Therefore, one-third of the hardness gives the flow stress at the plastic strain of $8 \%$ instead of the yield strength. However, for severely deformed materials additional straining after SPD usually yields only a slight hardening, and thus one-third of the hardness is an acceptable approximation of the yield strength. In the following, the strength contributions of dislocations and grain size are calculated. The yield strength caused by dislocations can be obtained from the Taylor equation as [37]:

$$
\sigma_{\text {Taylor }}=\alpha M^{T} G b \sqrt{\rho},
$$

where $\alpha$ is a constant describing the strengthening effect for a unit density of dislocations, $G$ is the shear modulus, $b$ is the modulus of the Burgers vector calculated as the lattice parameter divided by the square-root of two for fcc crystals $\left(0.255 \mathrm{~nm}\right.$ for the present HEA) and $M^{T}$ is the Taylor factor (3.06 was selected as a strong texture was not observed). According to a previous study on a CoCrFeMnNi HEA [26,38], the value of the shear modulus was chosen as $\sim 80 \mathrm{GPa}$. The influence of grain size on yield strength can be described by the Hall-Petch relationship [39,40]:

$$
\sigma_{H P}=\frac{k}{\sqrt{d}},
$$

where $k$ is a constant depending on the investigated material and $d$ is the average grain size.

Assuming a simple linear additivity of the hardening contributions of dislocations and grain size, the yield strength can be calculated as:

$$
\sigma_{y}=\sigma_{0}+\sigma_{\text {Taylor }}+\sigma_{H P},
$$

where $\sigma_{0}$ is the friction stress describing the resistance of the defect-free lattice against plastic deformation. The value of $\sigma_{0}$ was taken as $\sim 200 \mathrm{MPa}$ in accordance with previous studies on the CoCrFeMnNi HEA [26,41,42]. In eqs. (6-8), there are two unknown parameters for the present HEA, namely $\alpha$ and $k$ in the Taylor and Hall-Petch equations, respectively. These values were determined by searching for the best agreement between the estimated yield strength and the values calculated from eq. (8) for the center and the periphery of the disks processed by 1/4, 1/2, 1 and 2 turns (thus. altogether eight studied locations). It should be noted that, due to the $1 \mathrm{~mm}$ height of the X-ray spot on the illuminated surface, the estimated 
yield strength was obtained by averaging the strength values obtained for distances from the disk center between -0.5 and $0.5 \mathrm{~mm}$. At the periphery, the strength determined at $+/-4 \mathrm{~mm}$ from the disk center was taken as the estimated value (see Fig. 1). It is also noted that for the periphery of the disks processed for 1 and 2 turns the grains were highly twinned as indicated by the XLPA and TEM observations, therefore the twin boundary spacing was substituted for the grain size in the Hall-Petch relationship. The twin boundary spacing was calculated from the twin fault probability determined by XLPA using the equation given in section 3.3. Former studies [e.g., 43,44] showed that the same value of $k$ can be used in the Hall-Petch relationship for both the grain size and the twin boundary spacing. Although twin boundaries were also observed inside the coarse grains by EBSD (as in Fig. 4d), they were included in the HAGBs and therefore their effect was taken into account in the calculation of the average grain size.

The difference between the estimated and calculated yield strength was minimised by varying the values of $\alpha$ and $k$ using the method of least squares. This procedure gave $0.16 \pm$ 0.02 and $21 \pm 2 \mathrm{MPa} \cdot \mu \mathrm{m}^{1 / 2}$ for $\alpha$ and $k$, respectively. With these values, a relatively good agreement between the estimated and calculated yield strength values was achieved, as shown in Fig. 12. The estimated and the calculated yield strength values are listed in Table 2. The contributions of dislocations and grain/twin size to the yield strength are also listed. It can be seen that dislocations have a much higher hardening effect than the grain/twin size. The dislocation hardening parameter $\alpha$ for the present HPT-processed HEA samples has a relatively low value compared to other metals. For example, it was reported that $\alpha$ varies between 0.17 and 0.3 for $\mathrm{Cu}$ deformed at different strains [45]. A similar range was observed for SPD-processed fcc metals with different stacking fault energies [46]. The smaller values of $\alpha$ were obtained for materials with lower SFEs. For instance, for ultrafine-grained Ag processed by equal-channel angular pressing the value of $\alpha$ was 0.17 which is very close to the value determined for the CoCrFeMnNi HEA in this study. In addition, the SFE values are also similar: 16 [46] and $19 \mathrm{~mJ} / \mathrm{m}^{2}$ [30] for $\mathrm{Ag}$ and the CoCrFeMnNi HEA, respectively. As discussed earlier [46], the low SFE leads to a higher degree of dislocation dissociation which impedes the clustering of dislocations. It was shown previously [47] that the less clustered the dislocation structure, so the lower the value of $\alpha$. Therefore, the low SFE of the CoCrFeMnNi HEA appears to make a significant contribution to the relatively small value of $\alpha$.

\section{Summary and conclusions}


The evolution of the defect structure, grain size and hardness during HPT processing of an equiatomic $\mathrm{CoCrFeMnNi} \mathrm{HEA} \mathrm{was} \mathrm{studied.} \mathrm{The} \mathrm{following} \mathrm{conclusions} \mathrm{were} \mathrm{obtained:}$

1. In the initial sample, the average grain size was determined as $\sim 60 \mu \mathrm{m}$. After 2 turns of HPT, the grain size was refined to $\sim 30 \mathrm{~nm}$ at the periphery of the disk. At the same time, in the disk center the grain size was reduced only to $\sim 4 \mu \mathrm{m}$ after 2 turns, indicating a high sensitivity of grain refinement on the gradient in shear strain along the disk radius.

2. The dislocation density increased rapidly with increasing numbers of turns in HPT processing. After $1 / 4$ turn, high dislocation densities with values of $\sim 43$ and $\sim 91 \times 10^{14}$ $\mathrm{m}^{-2}$ were detected in the center and the periphery of the HPT disk, respectively. Further straining up to 2 turns increased the dislocation density to $\sim 126$ and $\sim 194 \times$ $10^{14} \mathrm{~m}^{-2}$ in the center and the periphery, respectively. The high shear strains at the edge of the disks processed by 1 and 2 turns of HPT yielded large twin fault probabilities of $\sim 2.2-2.7 \%$.

3. Similar to the microstructure, there was a large gradient in the hardness along the disk radius. After $1 / 4$ turn of HPT, the hardness increased from $\sim 1440 \mathrm{MPa}$ to $\sim 2400$ and $\sim 4860 \mathrm{MPa}$ in the center and the periphery of the disk, respectively. Even after 2 turns of HPT a large gradient in hardness remained along the disk radius. The maximum hardness value at the periphery of the disk processed by 2 HPT turns was measured as $\sim 5380 \mathrm{MPa}$.

4. A good correlation between the estimated and the calculated yield strength values was achieved using $\alpha=0.16$ and $k=21 \mathrm{MPa} \cdot \mu \mathrm{m}^{1 / 2}$ in the Taylor and Hall-Petch terms of yield strength. The relatively small value of $\alpha$ was attributed to the low SFE of the CoCrFeMnNi HEA since the clustering of highly dissociated dislocations in low SFE materials is hindered and the less clustered dislocation structure usually yields a small value of $\alpha$ in the Taylor equation.

\section{Acknowledgements}

This work was supported by the Hungarian Scientific Research Fund, OTKA, Grant No. K109021. The authors are grateful to Mr. Gábor Varga and Dr. Zoltán Dankházi for performing EBSD experiment. This work was also supported in part by the NRF Korea funded by MoE under Grant No. NRF-2016R1A6A1A03013422 and by MSIP under Grant No. NRF2016K1A4A3914691 (MK) and in part by the National Science Foundation of the United States under Grant No. DMR-1160966 (TGL). 


\section{References}

[1] J.W. Yeh, S.K. Chen, S.J. Lin, J.Y. Gan, T.S. Chin, T.T. Shun, C.H. Tsau, S.Y. Chang, Nanostructured high-entropy alloys with multiple principal elements: novel alloy design concepts and outcomes, Adv. Eng. Mater. 6 (2004) 299-303.

[2] B. Cantor, I.T.H. Chang, P. Knight, A.J.B. Vincent, Microstructural development is equiatomic multicomponent alloys, Mater. Sci. Eng. A 375-377 (2004) 213-218.

[3] D.B. Miracle, J.D. Miller, O.N. Senkov, C. Woodward, M.D. Uchic, J. Tiles, Exploration and development of high entropy alloys for structural applications, Entropy 16 (2014) 494525.

[4] Z. Zou, H. Ma, R. Spolenak, Ultrastrong ductile and stable high-entropy alloys at small scales, Nature Comm. 6 (2015) 1-6.

[5] Y. Zhang, T.T. Zuo, Z. Tang, M.C. Gao, K.A. Dahmen, P.K. Liaw, Z.P. Lu, Microstructures and properties of high-entropy alloys, Prog. Mater. Sci. 61 (2014) 1-93.

[6] O.N. Senkov, J. Scott, S. Senkova, Microstructure and elevated temperature properties of a refractory TaNbHfZrTi alloy, J. Mater. Sci. 47 (2012) 4062-4074.

[7] G. Dirras, J. Gubicza, A. Heczel, L. Lilensten, J.-P. Couzinié, L. Perrière, Y. Guillot, A. Hocini, Microstructural investigation of plastically deformed Ti20Zr20Hf20Nb20Ta20 high entropy alloy by X-ray diffraction and transmission electron microscopy, Mater. Char. 108 (2015) 1-7.

[8] G. Dirras , H. Couque, L. Lilensten, A. Heczel, D. Tingaud, J.-P. Couzinié, L. Perrière, J. Gubicza, I. Guillot, Mechanical behavior and microstructure of Ti20Hf20Zr20Ta20Nb20 high-entropy alloy loaded under quasi-static and dynamic compression conditions, Mater. Char. 111 (2016) 106-113

[9] T.G. Langdon, Twenty-five years of ultrafine-grained materials: Achieving exceptional properties through grain refinement, Acta Mater. 61 (2013) 7035-7059.

[10] R.Z. Valiev, A.P. Zhilyaev, T.G. Langdon, Bulk Nanostructured Materials, Fundamentals and Applications, John Wiley \& Sons, Inc., Hoboken, New Jersey, 2014.

[11] A.P. Zhilyaev, T.G. Langdon, Using high-pressure torsion for metal processing: Fundamentals and applications, Prog. Mater. Sci. 53 (2008) 893-979.

[12] D.H. Lee, I.C. Choi, M.Y. Seok, J. He, Z. Lu, J.Y. Suh, M. Kawasaki, T.G. Langdon, J.I. Jang, Nanomechanical behavior and structural stability of a nanocrystalline 
CoCrFeNiMn high-entropy alloy processed by high-pressure torsion, J. Mater. Res. 30 (2015) 2804-2815.

[13] H. Yuan, M.-H. Tsai, G. Sha, F. Liu, Z. Horita, Y. Zhu, J.T. Wang, Atomic-scale homogenization in an fcc-based high-entropy alloy via severe plastic deformation, J. Alloys Compd. 686 (2016) 15-23.

[14] Q.H. Tang, Y. Huang, Y.Y. Huang, X.Z. Liao, T.G. Langdon, P.Q. Dai, Hardening of an $\mathrm{Al}$ 10.3CoCrFeNi high entropy alloy via high-pressure torsion and thermal annealing, Mater. Lett. 151 (2015) 126-129.

[15] B. Schuh, F. Mendez-Martin, B. Völker, E.P. George, H. Clemens, R. Pippan, A. Hohenwarter, Mechanical properties, microstructure and thermal stability of a nanocrystalline $\mathrm{CoCrFeMnNi}$ high-entropy alloy after severe plastic deformation, Acta Mater. 96 (2015) 258-268.

[16] D.H. Lee, M.Y. Seok, Y. Zhao, I.C. Choi, J. He, Z. Lu, J.Y. Suh, U. Ramamurty, M. Kawasaki, T.G. Langdon, J.I. Jang, Spherical nanoindentation creep behavior of nanocrystalline and coarse-grained CoCrFeMnNi high-entropy alloys, Acta Mater. 109 (2016) 314-322.

[17] Y. Ma, G.J. Peng, D.H. Wen, T.H. Zhang, Nanoindentation creep behavior in a $\mathrm{CoCrFeCuNi}$ high-entropy alloy film with two different structure states, Mater. Sci. Eng. A 621 (2015) 111-117.

[18] J.Y. He, W.H. Liu, H. Wang, Y. Wu, X.J. Liu, T.G. Nieh, Z.P. Lu, Effects of Al addition on structural evolution and tensile properties of the FeCoNiCrMn high-entropy alloy system, Acta Mater. 62 (2014) 105-113.

[19] K.Y. Tsai, M.H. Tsai, J.W. Yeh, Sluggish diffusion in Co-Cr-Fe-Mn-Ni high-entropy alloys, Acta Mater. 61 (2013) 4887-4897.

[20] R.B. Figueiredo, P.H.R. Pereira, M.T.P. Aguilar, P.R. Cetlin, T.G. Langdon, Using finite element modelling to examine the flow processes in quasi-constrained high-pressure torsion, Acta Mater. 60 (2012) 3190-3198.

[21] J. Nelson, D. Riley, An experimental investigation of extrapolation methods in the derivation of accurate until-cell dimensions of crystals, Proc. Phys. Soc. Lond. 57 (1945) $160-177$.

[22] G. Ribárik, J. Gubicza, T. Ungár, Correlation between strength and microstructure of ball-milled Al-Mg alloys determined by X-ray diffraction, Mater. Sci. Eng. A 387-389 (2004) 343-347. 
[23] G.A. Salishchev, M.A. Tikhonovsky, D.G. Shaysultanov, N.D. Stepanov, A.V. Kuznetsov, I.V. Kolodiy, A.S. Tortika, O.N. Senkov, Effect of Mn and V on structure and mechanical properties of high-entropy alloys based on $\mathrm{CoCrFeNi}$ system, J. Alloys Compd. 591 (2014) 11-21.

[24] E.J. Mittemeijer, U. Welzel, The "state of the art" of the diffraction analysis of crystallite size and lattice strain, Z. Kristallogr. 223 (2008) 552-560.

[25] T. Ungár, I. Dragomir, Á. Révész, A. Borbély, The contrast factors of dislocations in cubic crystals: the dislocation model of strain anisotropy in practice, J. Appl. Cryst. 32 (1999) 992-1002.

[26] B. Gludovatz, E.P. George, R.O. Ritchie, Processing, Microstructure and Mechanical Properties of the CrMnFeCoNi, JOM, Vol. 67, No. 10 (2015) 2262-2270.

[27] A. Borbély, J. Dragomir-Cernatescu, G. Ribárik, T. Ungár, Computer program ANIZC for the calculation of diffraction contrast factors of dislocations in elastically anisotropic cubic, hexagonal and trigonal crystals, J. Appl. Cryst. 36 (2003) 160-162.

[28] T. Ungár, J. Gubicza, G. Ribárik, A. Borbély, Crystallite Size-Distribution and Dislocation Structure Determined by Diffraction Profile Analysis: Principles and Practical Application to Cubic and Hexagonal Crystals, J. Appl. Cryst. 34 (2001) 298-310.

[29] M. Kawasaki, Different models of hardness evolution in ultrafine-grained materials processed by high-pressure torsion, J. Mater. Sci. 49 (2014) 18-34.

[30] A.J. Zaddach, C. Niu, C.C. Koch, D.L. Irving, Mechanical properties and stacking fault energies of NiFeCrCoMn high-entropy alloy, JOM 65 (2013) 1780-1789.

[31] J. Gubicza, N. Q. Chinh, J. L. Lábár, Z. Hegedüs, T. G. Langdon, Principles of selfannealing in silver processed by equal-channel angular pressing: The significance of a very low stacking fault energy, Mater. Sci. Eng. A. 527 (2010) 752-760.

[32] Z. Hegedüs, J. Gubicza, M. Kawasaki, N.Q. Chinh, Zs. Fogarassy, T.G. Langdon, Microstructure of low stacking fault energy silver processed by different routes of severe plastic deformation, J. Alloys Compd. 536S (2012) S190- S193.

[33] T.M. Smith, M.S. Hooshmand, B.D. Esser, F. Otto, D.W. McComb, E.P. George, M. Ghazisaeidi, M.J. Mills, Atomic-scale characterization and modeling of $60^{\circ}$ dislocations in a high-entropy alloy, Acta Mater. 110 (2016) 352-363.

[34] J. Gubicza, Defect Structure in Nanomaterials, Woodhead Publishing, Cambridge, UK, 2012. 
[35] F. Otto, N.L. Hanold, E.P. George, Microstructural evolution after thermomechanical processing in an equiatomic, single-phase $\mathrm{CoCrFeMnNi}$ high-entropy alloy with special focus on twin boundaries, Intermetallics 54 (2014) 39-48.

[36] G. Laplanche, A. Kostka, O.M. Horst, G. Eggeler, E.P. George, Microstructure evolution and critical stress for twinning in the CrMnFeCoNi high-entropy alloy, Acta Materialia 118 (2016) 152-163.

[37] G.I. Taylor, Plastic strain in metals, J. Inst. Met. 62 (1938) 307-324.

[38] G. Laplanche, P. Gadaud, O. Horst, F. Otto, G. Eggeler, E.P. George, Temperature dependencies of the elastic moduli and thermal expansion coefficient of an equiatomic, single-phase CoCrFeMnNi high-entropy alloy, J. Alloys Compd. 623 (2015) 348-353.

[39] N.J. Petch, The cleavage strength of polycrystals, J. Iron Steel Inst. 173 (1953) 25-28.

[40] E.O. Hall, The deformation and ageing of mild steel; discussion of results, Proc. Phys. Soc. Lond. B 64, (1951) 47-753.

[41] A. Gali, E.P. George, Tensile properties of high- and medium-entropy alloys, Intermetallics 39 (2013) 74-78.

[42] F. Otto, A. Dlouhy, C. Somsen, H. Bei, G. Eggeler, E.P. George, The influences of temperature and microstructure on the tensile properties of a $\mathrm{CoCrFeMnNi}$ high-entropy alloy, Acta Mater. 61 (2013) 5743-5755.

[43] K. Lu, L. Lu, S. Suresh, Strengthening materials by engineering coherent internal boundaries at the nanoscale, Science 324 (2009) 349-352.

[44] B.B. Rath, M.A. Imam, C.S. Pande, Nucleation and growth of twin interfaces in fcc metals and alloys, Mater. Phys. Mech. 1 (2000) 61-66.

[45] E. Schafler, K. Simon, S. Bernstorff, P. Hanák, G. Tichy, T. Ungár, M.J. Zehetbauer, Second order phase transformation of the dislocation structure during plastic deformation determined by in situ synchrotron X-ray diffraction, Acta Mater. 53 (2005) 315-322.

[46] J. Gubicza, N. Q. Chinh, J.L. Lábár, S. Dobatkin, Z. Hegedűs, T. G. Langdon, Correlation between microstructure and mechanical properties of severely deformed metals, J. Alloys Compd. 483 (2009) 271-274.

[47] F. Hernández Olivares, J. Gil Sevillano, A quantitative assessment of forest-hardening in FCC metals, Acta metall. 35 (1987) 631-641. 


\section{Figure and table captions}

Fig. 1: Schematic depiction of the X-ray beam spot on the HPT-processed disks.

Fig. 2: (a) EBSD image and (b) SEM-BSE picture for the initial as-cast sample. A part of (b) is shown in a higher magnification in (c). The chemical composition was investigated by EDS along the white dotted line in (c). The fractions of the five constituents versus the position along the dotted line are shown in (d).

Fig. 3: EBSD images showing the microstructures at (a) the center, (b) the half-radius and (c) the periphery of the HEA disk processed by $1 / 4$ turn of HPT. The white arrows in (b) indicate twins formed due to HPT deformation.

Fig. 4: EBSD images showing the center of the disks in the HEA sample after (a) $1 / 2$, (b) 1 and (c) 2 turns of HPT. The thick black lines in (d) represent $\Sigma 3$ boundaries and some twin crystals are indicated by white arrows. The color code for the maps is shown in the inset in Fig. 4a.

Fig. 5: TEM images showing at the periphery of the disks processed by (a) $1 / 2$, (b) 1 (c) and 2 turns of HPT.

Fig. 6: Bright-field TEM images showing twinned grains at the periphery of the disk processed by 1 turn of HPT.

Fig. 7: The spatial distribution of the constituents in (a) the center and (b) the periphery of the CoCrFeMnNi HEA disk processed for $1 / 4$ turn and in (c) the center and (d) the periphery for 2 turns of HPT.

Fig. 8: Schematic showing that the total diffraction profile can be visualized as a sum of individual microstructural profiles scattered from regions with different lattice spacings. $\kappa$ is the modulus of the scattering vector.

Fig. 9: (a) Reflection 200 for the initial material, as well as for the center and the periphery, of the disks processed for $1 / 4$ and 2 turns of HPT, respectively. (b) the integral breadth versus the 
momentum of the diffraction vector, $g$ (Williamson-Hall plot), for the initial material, as well as for the center and the periphery of the disks processed for $1 / 4$ and 2 turns of HPT, respectively. (c) CMWP fitting for the center of the disk processed by $1 / 4$ turn.

Fig. 10: (a) The grain size determined by EBSD or TEM, (b) the diffraction domain size and (c) the dislocation density obtained by XLPA as a function of shear strain imposed by HPT.

Fig. 11: The Vickers microhardness versus the distance from the center (a) and the shear strain (b) for disks processed by HPT for $1 / 4,1 / 2,1$ and 2 turns. The hardness plotted in (b) was calculated as the average of the two values obtained for the same distance from center. The dashed line shows the average hardness for the initial sample without HPT. The error bars indicate the uncertainties in the hardness values.

Fig. 12: The estimated yield strength versus the values calculated from eq. (8) for the center and the periphery of the disks processed by $1 / 4,1 / 2,1$ and 2 turns.

Table 1: The grain size $(d)$ determined by electron microscopy (EBSD or TEM), the areaweighted mean diffraction domain size $\left(\langle x\rangle_{\text {area }}\right)$, the dislocation density $(\rho)$ and the twin-fault probability $(\beta)$ obtained by XLPA. The corresponding shear strain values are also shown. The calculation details of the shear strain are given in the last paragraph of section 3.3.

Table 2. The contributions of dislocations $\left(\sigma_{\text {Taylor }}\right)$ and grain/twin size $\left(\sigma_{\mathrm{HP}}\right)$ to the yield strength calculated from the Taylor and Hall-Petch relationships according to eqs. (6) and (7), respectively, and the value of the friction stress $\left(\sigma_{0}\right)$. The calculated yield strength $\left(\sigma_{\text {calculated }}\right)$ was obtained as the sum of the $\sigma_{0}, \sigma_{\text {Taylor }}$ and $\sigma_{\mathrm{HP}}$, while the estimated values $\left(\sigma_{\text {estimated }}\right)$ were determined as one-third of the hardness. The corresponding shear strain values are also shown. The calculation details of the shear strain are given in the last paragraph of section 3.3. 
Table 1: The grain size $(d)$ determined by electron microscopy (EBSD or TEM), the areaweighted mean diffraction domain size $\left(\langle x\rangle_{\text {area }}\right)$, the dislocation density $(\rho)$ and the twin-fault probability $(\beta)$ obtained by XLPA. The corresponding shear strain values are also shown. The calculation details of the shear strain are given in the last paragraph of section 3.3.

\begin{tabular}{|c|c|c|c|c|c|c|}
\hline $\begin{array}{c}\text { Number } \\
\text { of turns }\end{array}$ & location & $\gamma$ & $d$ & $\left\langle x>_{\text {area }}[\mathrm{nm}]\right.$ & $\begin{array}{c}\rho \\
{\left[10^{14} \mathrm{~m}^{-2}\right]}\end{array}$ & $\begin{array}{c}\beta \\
{[\%]}\end{array}$ \\
\hline \multirow{2}{*}{$1 / 4$} & center & 0.55 & $33 \pm 5 \mu \mathrm{m}$ & $51 \pm 6$ & $43 \pm 5$ & $<0.1$ \\
\cline { 2 - 7 } & periphery & 8.7 & $233 \pm 20 \mathrm{~nm}$ & $34 \pm 5$ & $91 \pm 9$ & $<0.1$ \\
\hline \multirow{2}{*}{$1 / 2$} & center & 1.4 & $19 \pm 2 \mu \mathrm{m}$ & $61 \pm 8$ & $66 \pm 8$ & $<0.1$ \\
\cline { 2 - 7 } & periphery & 22.1 & $37 \pm 6 \mathrm{~nm}$ & $28 \pm 4$ & $120 \pm 14$ & $<0.1$ \\
\hline \multirow{2}{*}{1} & center & 2.3 & $4.8 \pm 0.8 \mu \mathrm{m}$ & $20 \pm 3$ & $113 \pm 12$ & $<0.1$ \\
\cline { 2 - 7 } & periphery & 36.4 & $34 \pm 7 \mathrm{~nm}$ & $29 \pm 5$ & $185 \pm 21$ & $2.2 \pm 0.1$ \\
\hline \multirow{2}{*}{2} & center & 4.6 & $3.7 \pm 0.7 \mu \mathrm{m}$ & $22 \pm 4$ & $126 \pm 14$ & $<0.1$ \\
\cline { 2 - 7 } & periphery & 73.9 & $27 \pm 5 \mathrm{~nm}$ & $22 \pm 3$ & $194 \pm 20$ & $2.7 \pm 0.2$ \\
\hline
\end{tabular}


Table 2. The contributions of dislocations $\left(\sigma_{\text {Taylor }}\right)$ and grain/twin size $\left(\sigma_{H P}\right)$ to the yield strength calculated from the Taylor and Hall-Petch formulas according to eqs. (6) and (7), respectively, and the value of the friction stress $\left(\sigma_{0}\right)$. The calculated yield strength $\left(\sigma_{\text {calculated }}\right)$ was obtained as the sum of the $\sigma_{0}, \sigma_{\text {Taylor }}$ and $\sigma_{\mathrm{HP}}$, while the estimated values $\left(\sigma_{\text {estimated }}\right)$ were determined as one-third of the hardness. The corresponding shear strain values are also shown. The calculation details of the shear strain are given in the last paragraph of section 3.3.

\begin{tabular}{|c|c|c|c|c|c|c|}
\hline Location & $\gamma$ & $\begin{array}{c}\sigma_{\text {Taylor }} \\
{[\mathrm{MPa}]}\end{array}$ & $\begin{array}{c}\sigma_{\mathrm{HP}} \\
{[\mathrm{MPa}]}\end{array}$ & $\begin{array}{c}\sigma_{0} \\
{[\mathrm{MPa}]}\end{array}$ & $\begin{array}{c}\sigma_{\text {calculated }} \\
{[\mathrm{MPa}]}\end{array}$ & $\begin{array}{c}\sigma_{\text {estimated }} \\
{[\mathrm{MPa}]}\end{array}$ \\
\hline $1 / 4$ turn, center & 0.55 & $654 \pm 97$ & $4 \pm 1$ & 200 & $858 \pm 98$ & $841 \pm 50$ \\
\hline $1 / 4$ turn, periphery & 8.7 & $949 \pm 145$ & $44 \pm 6$ & 200 & $1193 \pm 151$ & $1540 \pm 103$ \\
\hline $1 / 2$ turn, center & 1.4 & $810 \pm 121$ & $5 \pm 1$ & 200 & $1015 \pm 122$ & $921 \pm 66$ \\
\hline $1 / 2$ turn, periphery & 22.1 & $1092 \pm 162$ & $109 \pm 16$ & 200 & $1401 \pm 178$ & $1627 \pm 107$ \\
\hline 1 turn, center & 2.3 & $1056 \pm 158$ & $10 \pm 1$ & 200 & $1266 \pm 159$ & $1223 \pm 78$ \\
\hline 1 turn, periphery & 36.4 & $1357 \pm 196$ & $192 \pm 28$ & 200 & $1749 \pm 224$ & $1676 \pm 97$ \\
\hline 2 turn, center & 4.6 & $1117 \pm 167$ & $11 \pm 2$ & 200 & $1328 \pm 169$ & $1292 \pm 93$ \\
\hline 2 turn, periphery & 73.9 & $1387 \pm 203$ & $251 \pm 32$ & 200 & $1838 \pm 235$ & $1758 \pm 100$ \\
\hline
\end{tabular}




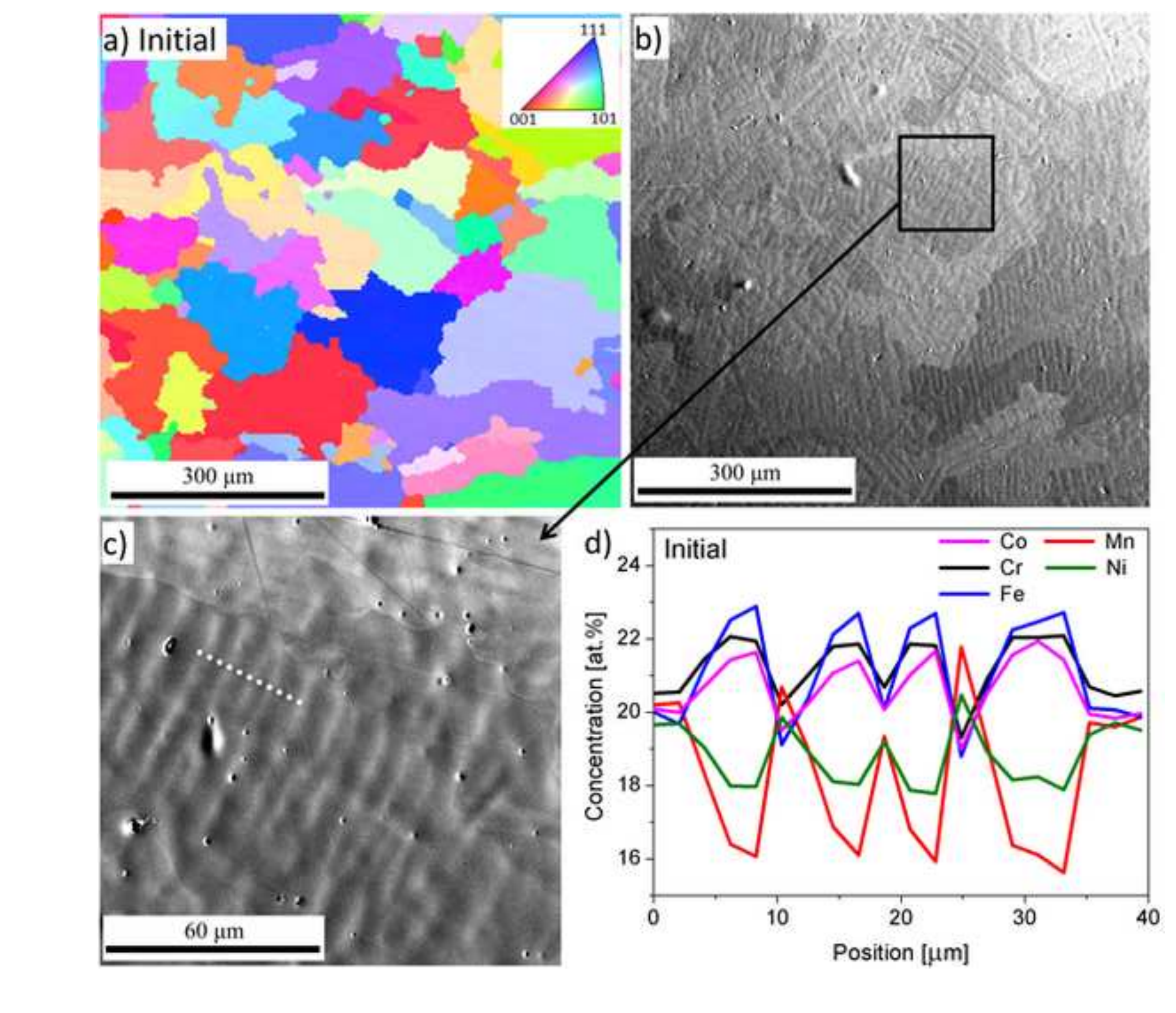

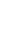

.

.

$x^{2}$

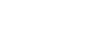

$$
\text { - }
$$

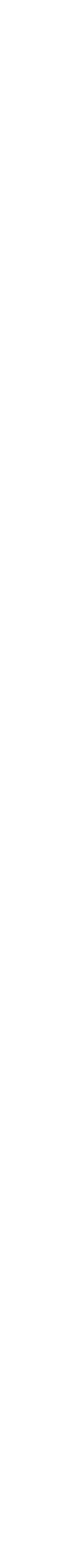




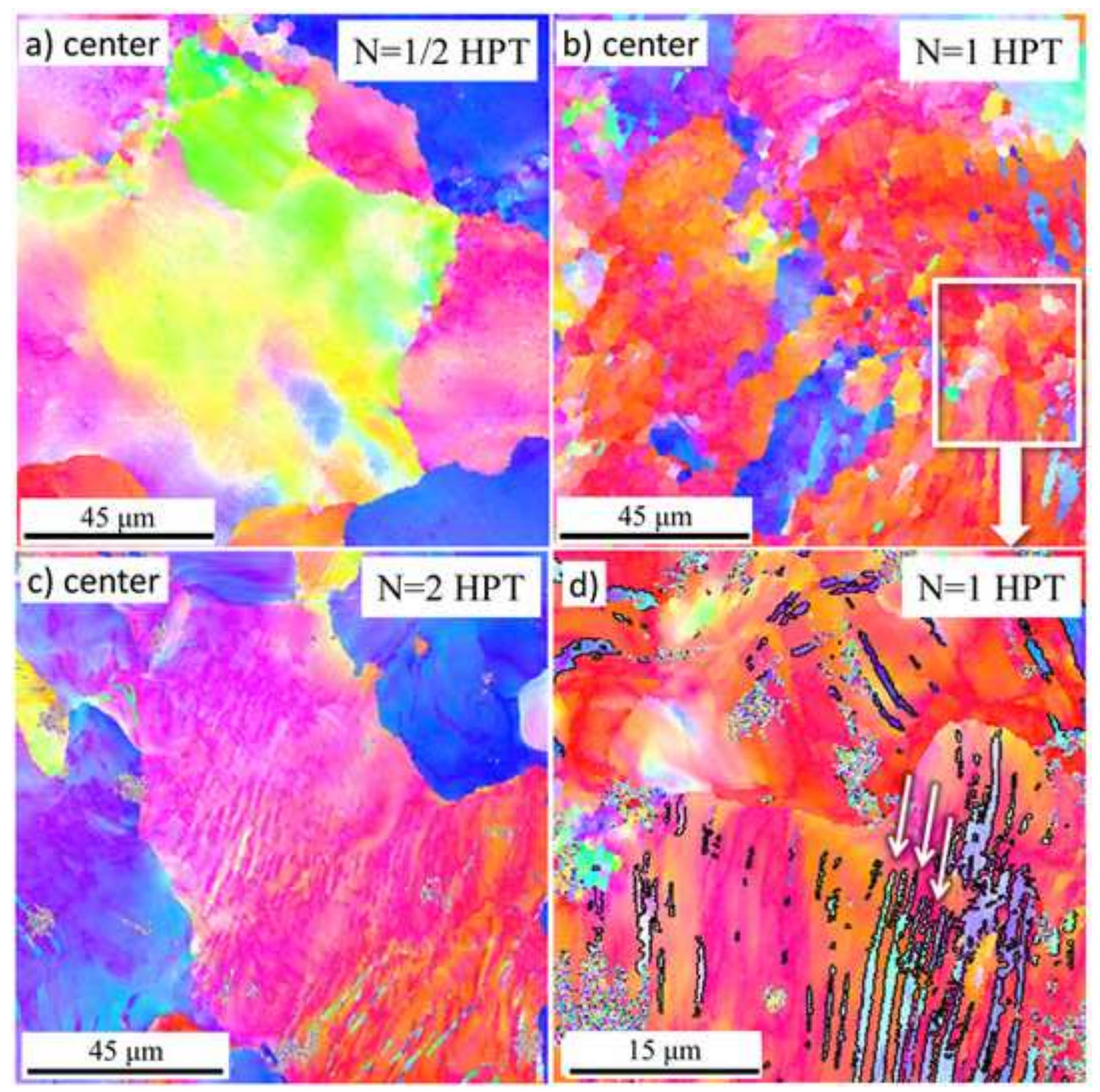




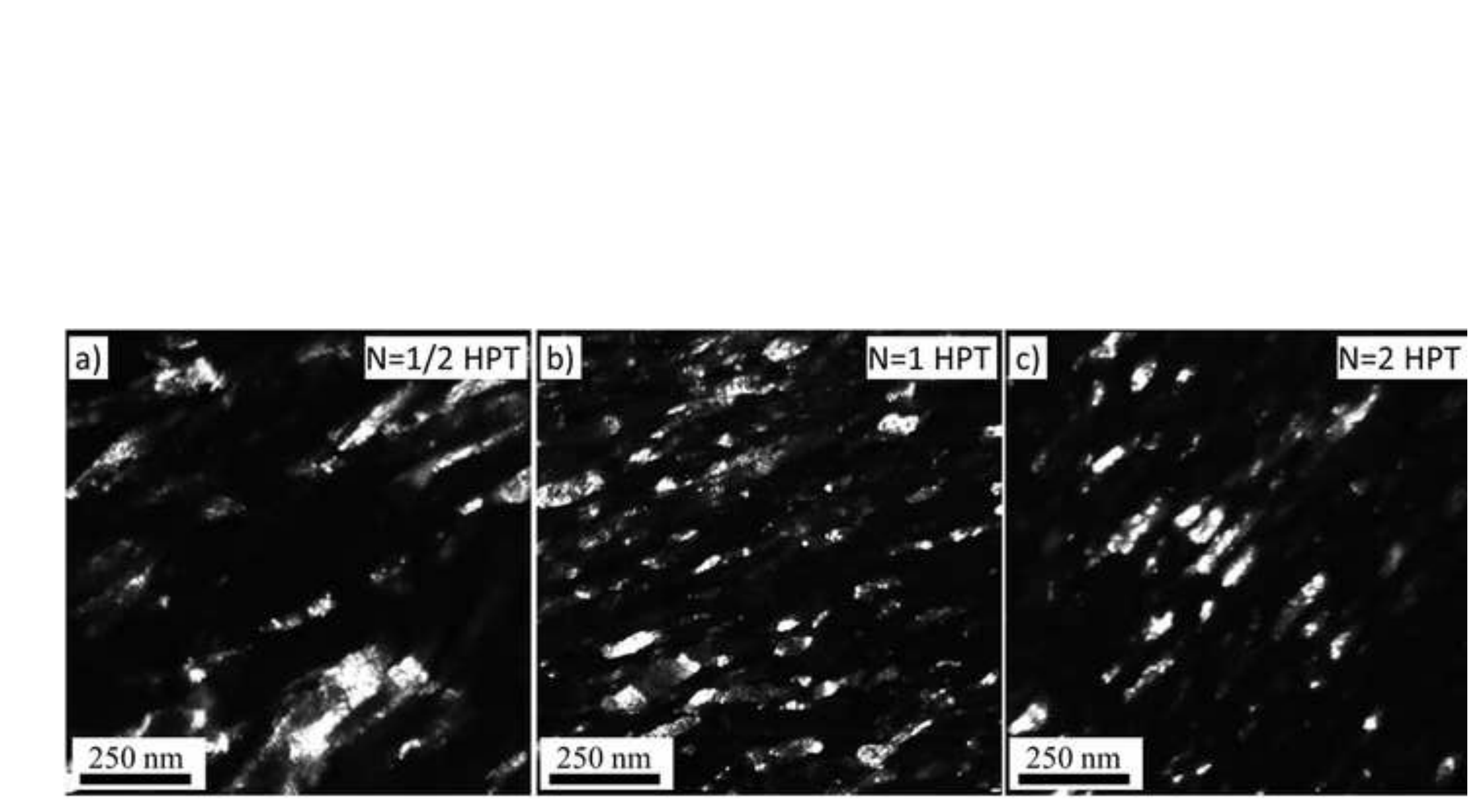




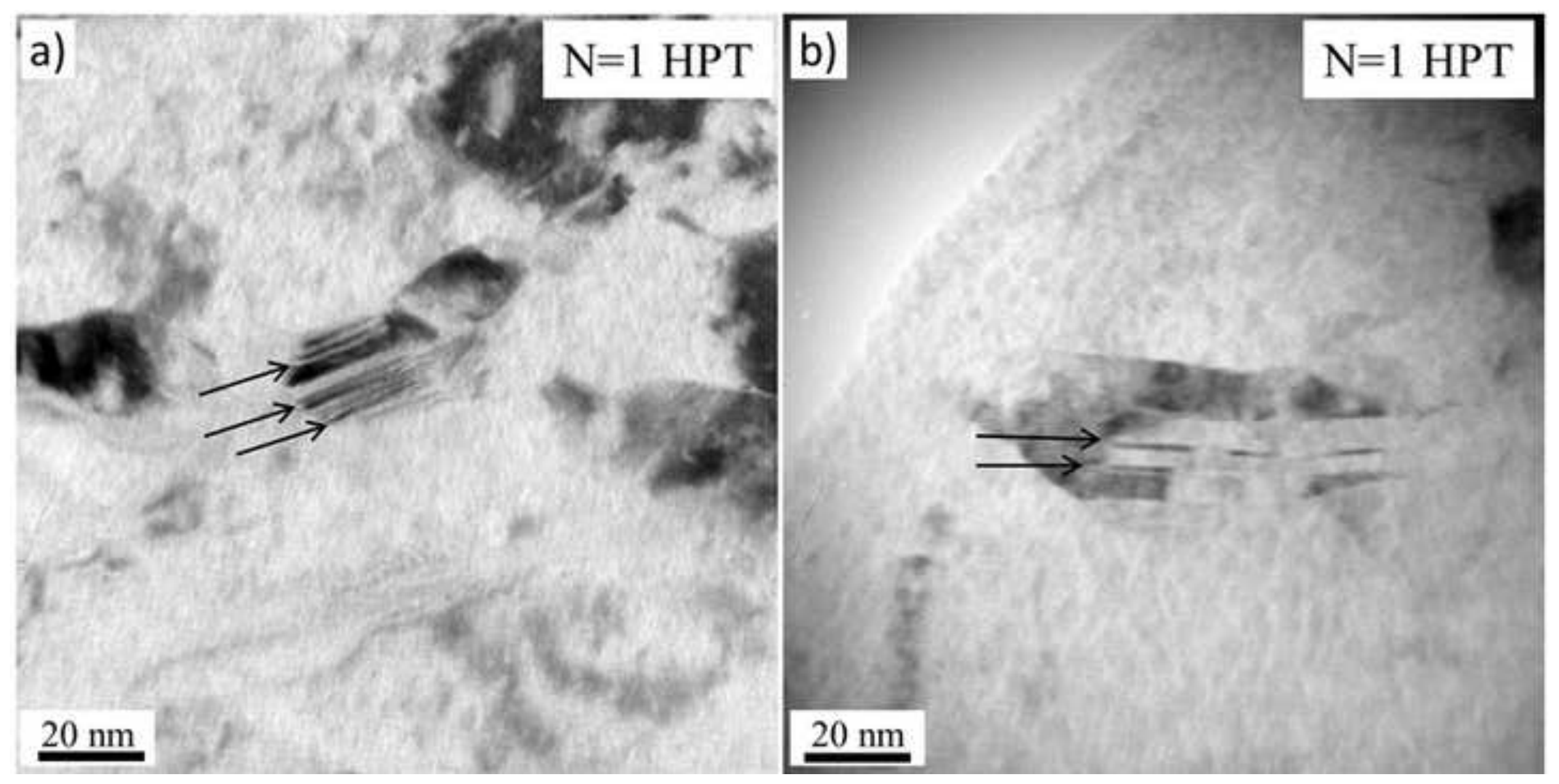



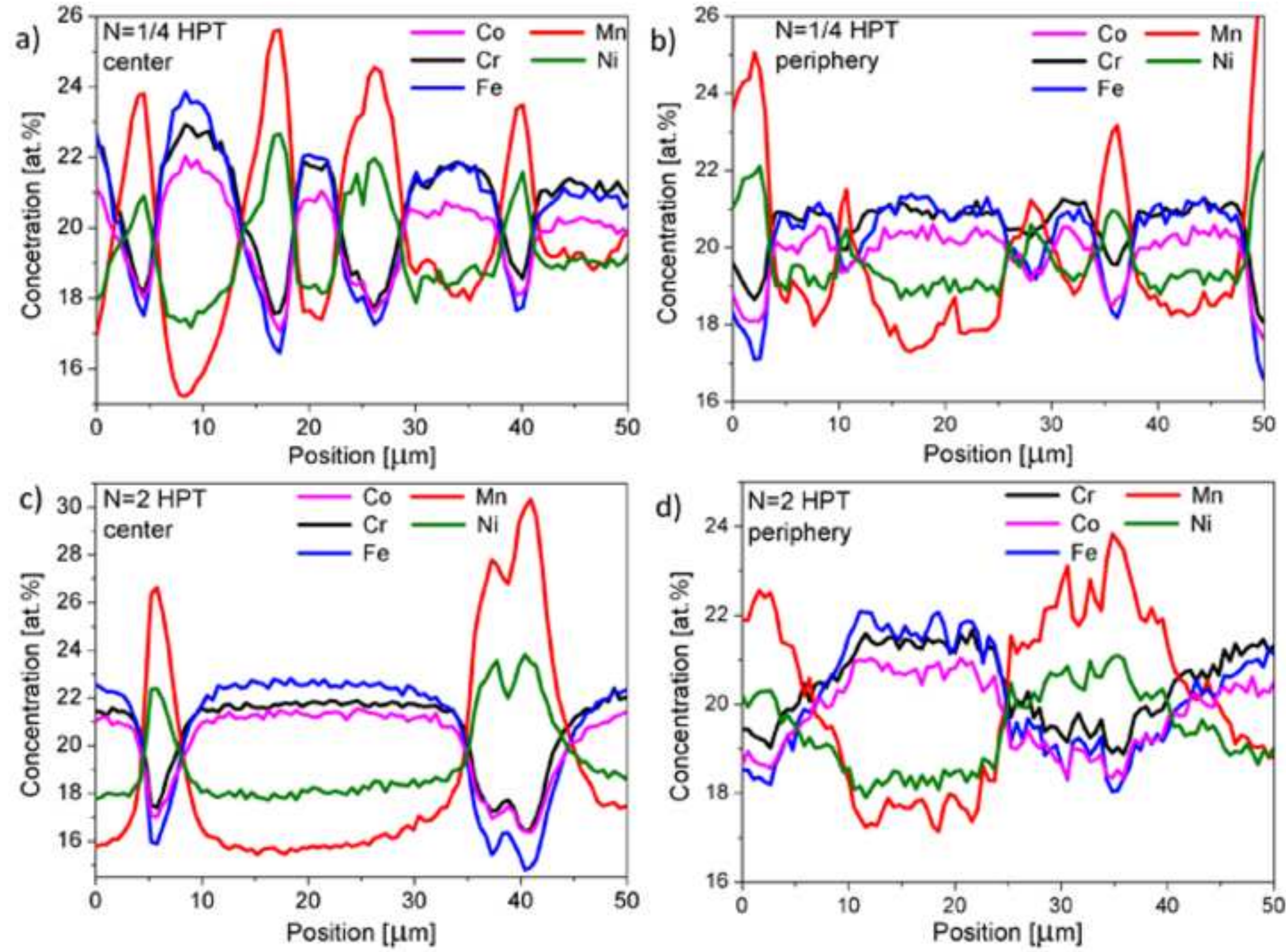


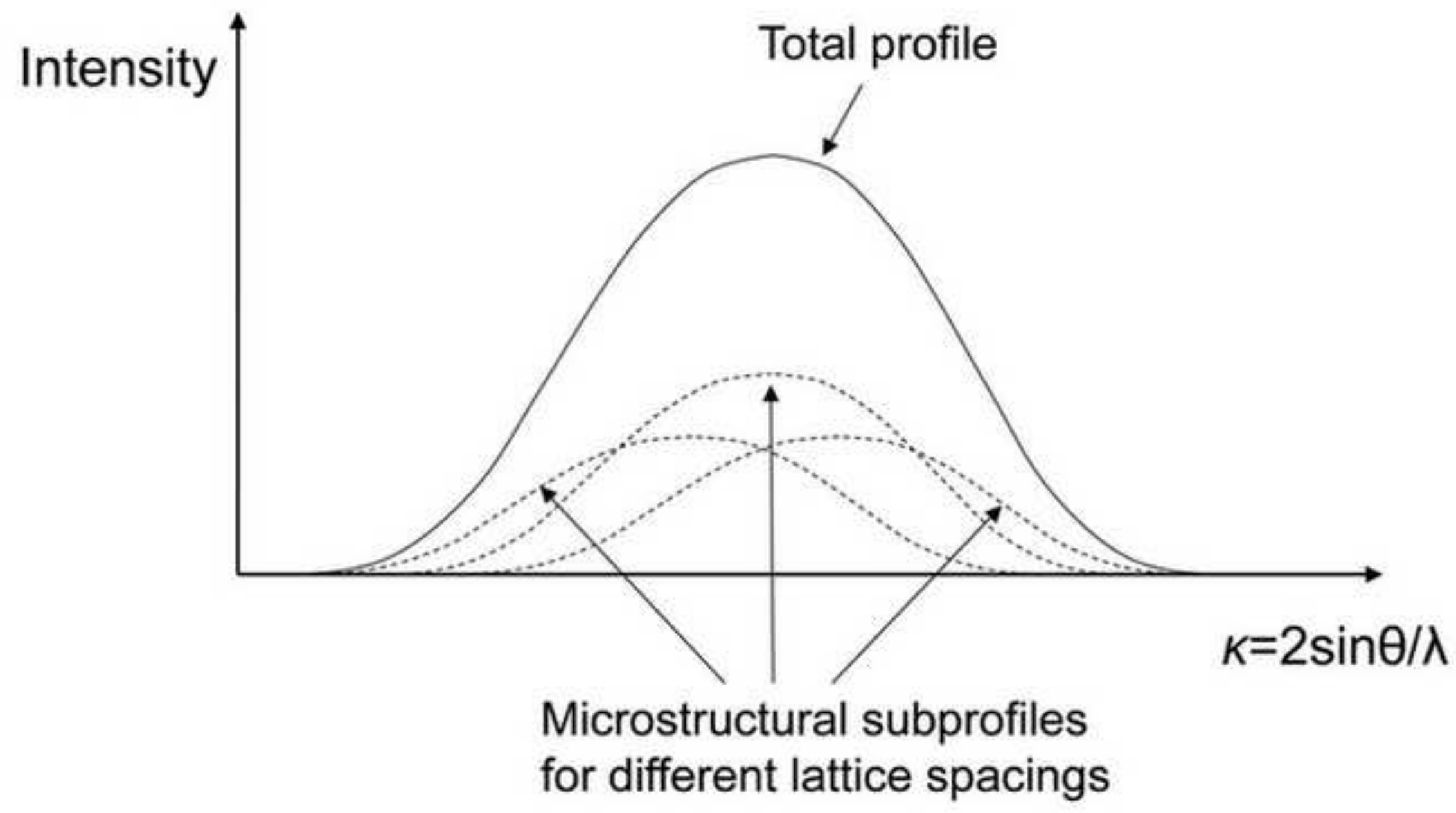



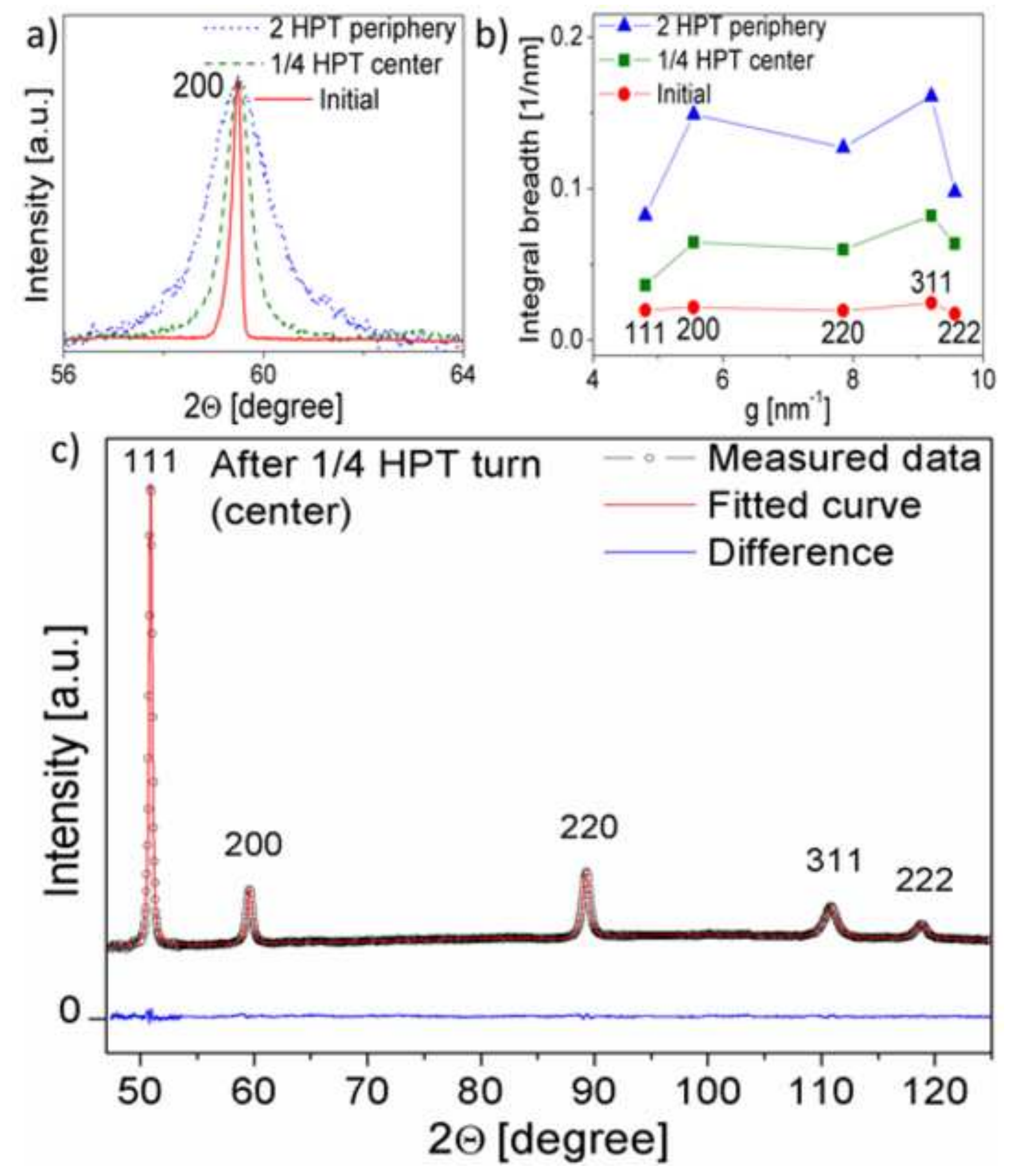

Figure 9 

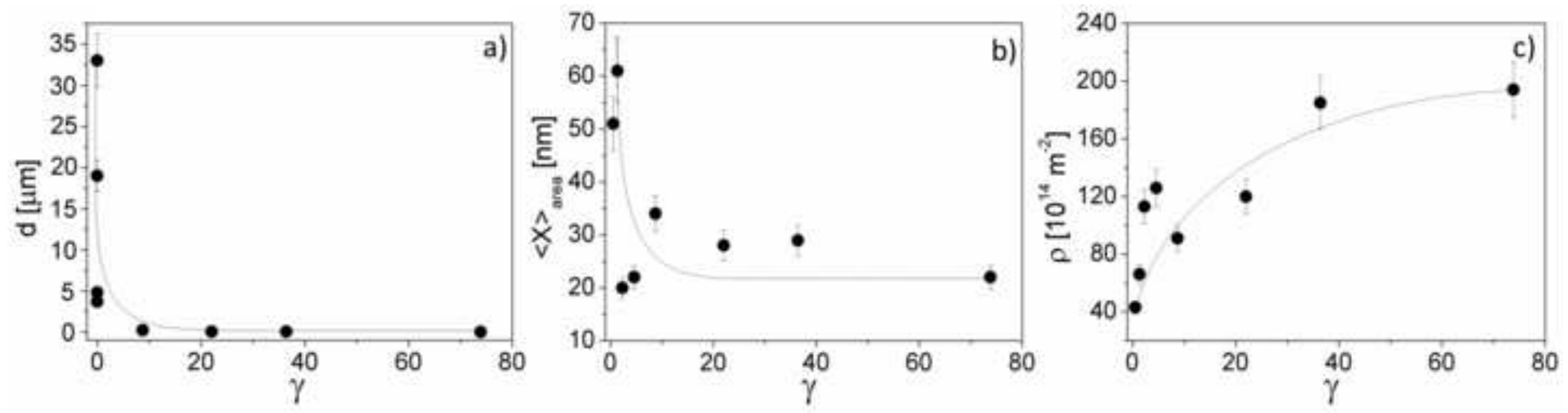

Figure 10 

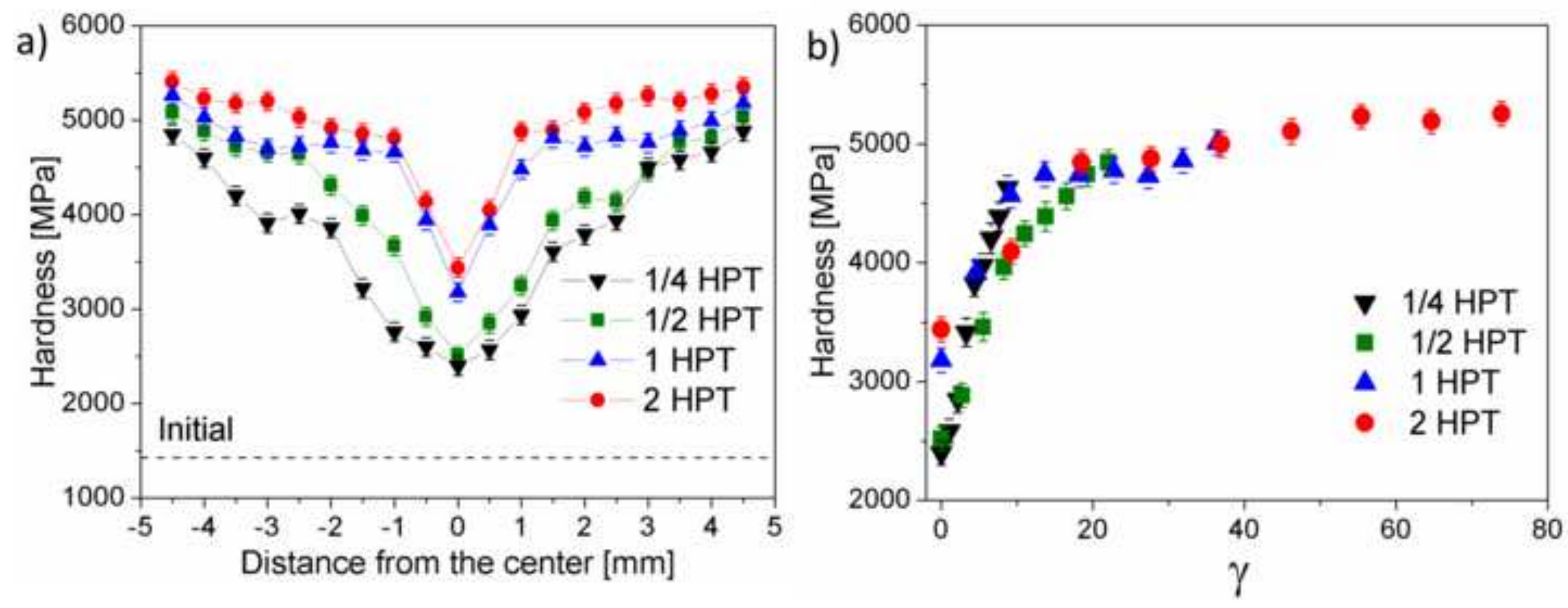


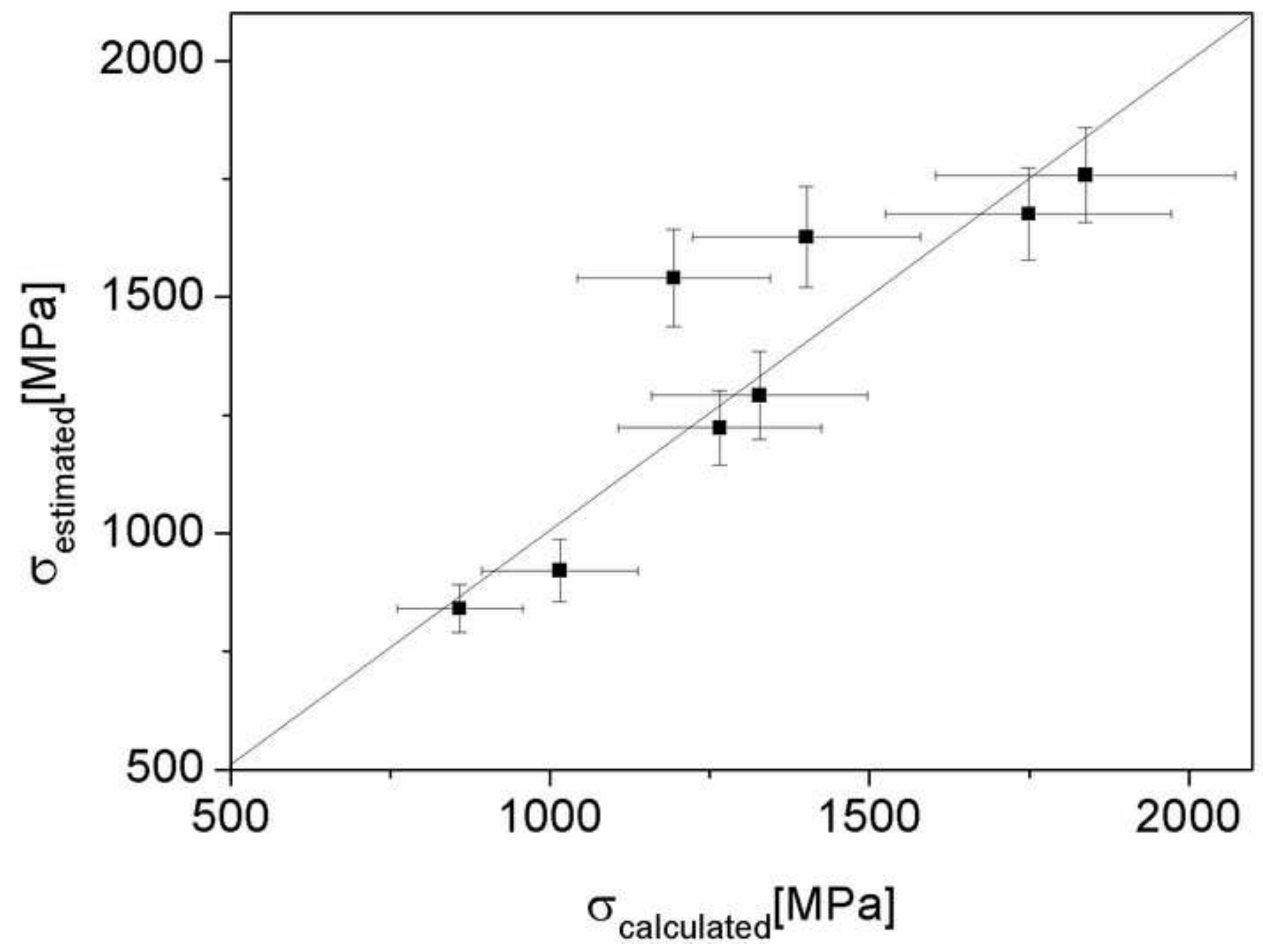

